\title{
PROPOSTA DE UM CONJUNTO DE INDICADORES DE DESEMPENHO EM AGROINDÚSTRIAS: O CASO DE USINAS SUCROALCOOLEIRAS
}

\section{PROPOSAL FOR PERFORMANCE INDICATORS IN AGRO-INDUSTRIES: THE CASE OF SUGAR ALCOHOL PLANTS}

\author{
Daniel Augusto Borges Pavani E-mail: d pavani@yahoo.com \\ Mário Otávio Batalha*E-mail: dmob@ufscar.br \\ *Universidade Federal de São Carlos (UFSCar), São Carlos, SP, Brasil
}

Resumo: Este trabalho tem por objetivo elaborar e propor um conjunto de indicadores de desempenho estratégicos e táticos para uma usina sucroalcooleira. Esses indicadores têm por característica abranger todas as áreas da usina para permitir aos tomadores de decisão uma visão global da empresa. Os indicadores foram obtidos por intermédio de uma pesquisa-ação que envolveu gestores das diversas áreas da usina. Os indicadores propostos utilizam o framework Performance Prism para sua construção e atendem às necessidades de gestão da empresa para os diretores da usina. Para demais níveis hierárquicos da empresa, o trabalho sugere que os ciclos propostos sejam replicados. O modelo proposto assume que indicadores de desempenho em uma usina sucroalcooleira deve contemplar aspectos ligados à industrialização da cana-de-açúcar e às atividades de produção agrícola. Neste sentido, são propostos 24 indicadores de desempenho que atendem às expectativas da usina. A equipe de diretores da usina colocará em prática os indicadores sugeridos e utilizará a pesquisa-ação proposta neste trabalho para expandir o conjunto de indicadores para o nível operacional. A principal contribuição deste artigo é a proposição de indicadores de desempenho que compreendem o conjunto de atividades de uma usina de cana-deaçúcar.

Palavras-chave: Indicadores de desempenho. Sistemas de medição de desempenho. Gestão no agronegócio. Usinas sucroalcooleiras.

\begin{abstract}
This paper aims to elaborate and propose a set of strategic and tactical performance indicators for a sugar and ethanol plants. These indicators are designed to cover all areas of the plant to enable decision makers to have a global view of the company. The indicators were obtained through an action research that involved managers of the plant's areas. The proposed indicators use the Performance Prism framework for their construction and meet the management needs of the company for the directors of the plant. For other hierarchical levels of the company, the work suggests that the proposed cycles are replicated. The proposed model assumes that performance indicators in a sugar and ethanol plant should include aspects related to the industrialization of sugarcane and to agricultural production activities. The main contribution of this article is the proposition of performance indicators that comprise the set of activities of a sugarcane mill.
\end{abstract}

Keywords: Performance indicators. Performance measurement systems. Management in agribusiness. Sugar and alcohol plants. 


\section{INTRODUÇÃO}

O agronegócio é vital para a economia brasileira. É o setor gerador de divisas mais importante do país. No ano de 2018 , as exportações do agronegócio atingiram um valor recorde superior a US\$101 bilhões, enquanto as importações para este setor se mantiveram na faixa de US\$ 14 bilhões. Isto representou um incremento de cerca de US\$ 87 bilhões na balança comercial do país, segundo o Ministério da Agricultura Pecuária e Abastecimento (MAPA, 2019a). Por sua vez, o complexo agroindustrial sucroenergético é parte importante do agronegócio brasileiro. Com uma participação de $7,3 \%$ do total, ele ocupou o quarto lugar nas exportações do agronegócio brasileiro em 2018. Não obstante esta importância, o setor sucroenergético assistiu a uma retração das exportações de cerca de 39\% em 2018 com relação ao ano anterior (MAPA, 2019a). Há casos em que é reportada, também, a redução da produtividade em safras seguidas de cana-de-açúcar: 2,5\% de redução quando comparada a safra de 2014/15 com a safra de 2013/14 (MOURA, 2014). A reversão deste quadro negativo revela a necessidade de as empresas melhorarem a eficiência e eficácia de suas operações. Uma gestão eficiente pode contribuir de forma importante para este movimento.

De fato, segundo Batalha e Silva (2007), a utilização de métodos e ferramentas de gestão modernas e adaptadas às especificidades do agronegócio podem auxiliar no aumento da competitividade das suas empresas. Os agentes produtivos das cadeias agroindustriais, entre eles os do complexo agroindustrial sucroalcooleiro, demandam cada vez mais sistemas de informações gerenciais que forneçam informações relevantes para a tomada de decisão. É nesse contexto que a utilização de indicadores de desempenho ganha importância como ferramenta de apoio à decisão gerencial. Os Sistemas de Medição de Desempenho (SMD) podem fornecer o quadro teórico necessário ao estabelecimento destes indicadores.

Alguns estudos propuseram conjuntos de indicadores de desempenho para usinas processadoras de cana-de-açúcar no Brasil, porém, para áreas específicas da empresa (BRUNSTEIN; TOMIYA, 1995; COSTA; MOLL, 1999; IANONNI; MORABITO, 2002; PAIVA; MORABITO, 2007; LIMA, 2009; SILVA, 2009; PELOIA; MILAN, 2010; SILVA et al., 2011; LÜTKEMEYER FILHO et al., 2015; PANTOJA et al., 2016). A questão desta pesquisa é se é possível estabelecer um conjunto de 
indicadores que atendam às necessidades dos diretores de uma usina de cana-deaçúcar e abordem todas as diversas áreas (agrícola, indústria, administrativa) da empresa.

Este artigo parte das ideias de Neely, Adams e Crowe (2001), propostas em um SMD que ficou conhecido como Performance Prism, para propor um conjunto de indicadores de desempenho para uma usina de cana-de-açúcar. Do ponto de vista teórico o artigo traz contribuições importantes. Os indicadores propostos promovem uma visão global (sistêmica) da usina, contemplando de forma integrada indicadores relativos ao desempenho industrial (processamento da cana) e ao desempenho agrícola. O pressuposto teórico para isso é o de que decisões tomadas na área agrícola impactam fortemente a parte industrial do processo. Por este motivo, o estabelecimento dos indicadores de desempenho deve ir além dos portões da fábrica para alcançarem também a parte agrícola da produção. Sob este ponto de vista, trata-se de considerar o sistema "produção agrícola e industrial" como um conjunto integrado de produção e espaço de análise relevante para a tomada de decisão (FERREIRA; BATALHA; DOMINGOS, 2016).

O procedimento metodológico da parte empírica da pesquisa valeu-se de uma Pesquisa-Ação. Foram coletados dados primários em uma usina sucroalcooleira, com entrevistas a gestores de áreas. Uma minuciosa análise documental nos procedimentos existentes na empresa também foi realizada.

A segunda seção desse artigo apresenta referenciais teóricos sobre sistemas de medição de desempenho, enfatizando o framework Performance Prism. $\mathrm{Na}$ terceira seção é apresentado o setor sucroenergético no Brasil e indicadores de desempenho encontrados na literatura para este setor. A seção seguinte relata os procedimentos metodológicos usados na pesquisa. A apresentação e análise dos resultados é feita na quinta seção e, na última seção estão descritas as considerações finais do artigo.

\section{SISTEMAS DE MEDIÇÃO DE DESEMPENHO E O PERFORMANCE PRISM}

Os Sistemas de Medição de Desempenho (SMDs) auxiliam na implementação e acompanhamento das estratégias empresariais. De acordo com Kaplan e Norton (1997), um framework desenvolvido para criação de indicadores de desempenho 
deve servir de suporte para o desenvolvimento de um novo sistema gerencial: "O sistema de indicadores deve ser apenas um meio para se alcançar uma meta ainda mais importante - um sistema de gestão estratégica que ajude os executivos a implementar e obter feedback sobre sua estratégia" (KAPLAN; NORTON, 1997, p. 283-284). De acordo com Silva (2009), quando os gestores de empresas formulam suas estratégias, eles devem avaliar diversas alternativas possíveis para o negócio. Quanto maior o número de alternativas viáveis, mais complexa é a análise delas, porém, existe a possibilidade de se extrair maiores informações sobre o problema de decisão.

Segundo Bititci et al. (2018), ao longo do tempo, os trabalhos encontrados na literatura evoluíram de medição de desempenho (o que medir) para gestão de desempenho (como usar as medições para gerenciar o desempenho das organizações). Para esses autores, os SMDs consistem nos elementos chave de um sistema de controle, ou seja, medir, comparar, analisar e agir. Smith e Bititci (2017) confirmam a importância da medição de desempenho para empresas na medida em que há uma crescente ênfase em melhorar os SMDs e práticas de gestão de desempenho para melhorar o nível de envolvimento e o desempenho dos funcionários.

Para Neely e Adams (2015) as medições de desempenho são desenvolvidas para ajudar os gerentes a estabelecer seus objetivos e guiar a equipe na tarefa de alcançá-los. Para estes autores, as empresas criam estratégias que geram listas de atividades de melhoria e iniciativas de gestão que, quando implementadas, possibilitam que as empresas entreguem valor aos seus múltiplos stakeholders investidores, clientes, intermediários, funcionários, fornecedores, reguladores e comunidade. Por este motivo, para Neely et al. (2001), a primeira e fundamental perspectiva a ser considerada na construção de um sistema de medição de desempenho deve ser a perspectiva dos stakeholders.

A literatura disponibiliza diversos frameworks teóricos destinados à construção de sistemas de medição de desempenho e de indicadores de desempenho. O Performance Measurement Matrix destaca-se por ser um framework que permite integrar diversas dimensões de avaliação de desempenho em uma matriz onde os indicadores são classificados em internos e externos, de custo e nãocusto. (STRITESKA; SPICKOVA, 2012). 
O framework Performance Pyramid, proposto por Lynch e Cross (1991), foi desenvolvido para facilitar a coordenação estratégica em empresas que atuam em vários segmentos. Ele tem por característica traduzir a visão e a estratégia globais da empresa em objetivos compreensíveis e acessíveis aos níveis hierárquicos inferiores da companhia ao mesmo tempo em que comunica os resultados das medidas de desempenho à equipe dirigente da organização. Nesta ótica, ele busca repartir as atividades da empresa em camadas estratégicas de avaliação de desempenho para atingir as eficiências interna e externa desejadas (NILSSON; OLVE, 2001).

O Balanced Scorecard (BSC) é o framework de SMD mais conhecido e adotado no mundo (STRITESKA; SPICKOVA, 2012). Esse framework provê uma abordagem estruturada para identificar oportunidades e ameaças e traduzir a estratégia das empresas em metas, alvos e tarefas passíveis de serem atingidas. Para atingir seus objetivos, o BSC propõe o desenvolvimento de medidas associadas a quatro perspectivas (econômico-financeira, clientes, processos internos e aprendizado e crescimento) que se conectam e ajudam a implementar uma estratégia consistente, formada por um conjunto de hipóteses com encadeamento lógico (KAPLAN; NORTON, 1992).

Os frameworks descritos, segundo Neely et al. (2001) são focados em atender às estratégias das empresas e não consideram adequadamente as características de funcionários da empresa, fornecedores, intermediários, reguladores, comunidade local ou grupos de pressão. Esses agentes podem ter impacto fundamental no desempenho e sucesso da empresa e devem ser os principais responsáveis pelo sucesso de um programa de desempenho. Todas essas partes, bem como os gestores da empresa e demais partes interessadas na empresa são os chamados stakeholders.

O framework Performance Prism proposto por Neely et al. (2001) como forma de contribuir para diminuir este problema é representado graficamente por um prisma. Ele é composto por cinco facetas, sendo a superior e a inferior focadas na Satisfação dos Stakeholders e na Contribuição dos Stakeholders, respectivamente. As outras três faces do prisma são construídas com a Estratégia, os Processos e as Capacidades. A proposta estrutural do Performance Prism de desempenho pode ser vista na Figura 1. 
Figura 1 - Sistema de medição de desempenho utilizando o framework do performance prism

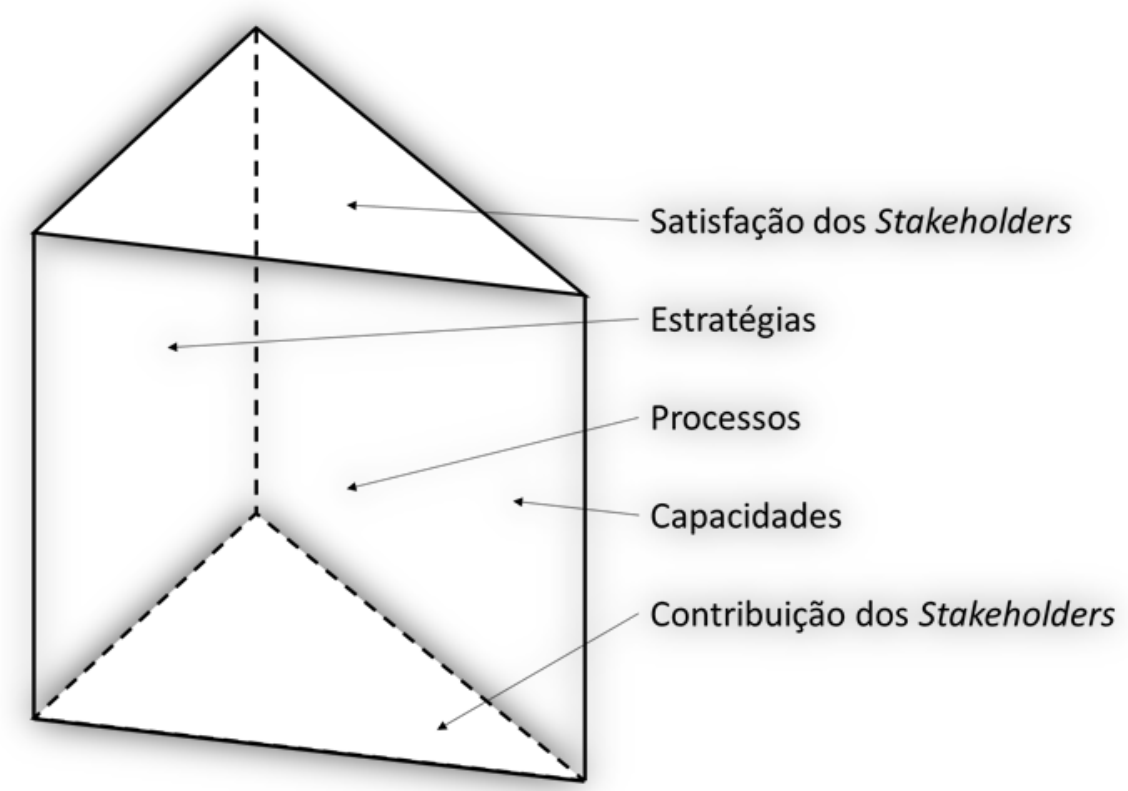

Fonte: Adaptado de Neely e Adams (2015).

Para construir os indicadores segundo a ótica do Performance Prism, os autores Neely e Adams (2015) afirmam que cada faceta deve responder a perguntas específicas que atendam a cada perspectiva:

- Para a perspectiva da Satisfação dos Stakeholders, a pergunta a ser respondida pelos gestores é: Quem são os stakeholders mais influentes e do que eles precisam?

- Após o endereçamento dessa resposta, passa-se à questão referente à segunda perspectiva, a Estratégia: Quais estratégias a companhia deve adotar para garantir que as necessidades e os desejos dos stakeholders sejam atingidos?

- A terceira faceta do Performance Prism, a dos Processos, deve responder à questão: Quais processos a empresa precisa empreender para permitir que a estratégia seja executada?

- A pergunta chave para a quarta faceta, a de Capacidades, é: Quais capacidades ou habilidades a empresa deve adquirir para operar os processos agora e no futuro?

- Finalmente, a quinta faceta do prisma, a Contribuição dos Stakeholders é incluída como um componente separado, que deve reconhecer que não 
apenas a organização entrega valor para os stakeholders, como estes também contribuem para o crescimento da empresa, respondendo à questão: Quais contribuições a empresa recebe de seus stakeholders quando mantém e desenvolve suas capacidades?

O Performance Prism tem como pontos fortes, segundo Striteska e Spickova (2012): contemplar novos stakeholders que são usualmente negligenciados quando se cria medição de desempenho; considerar a contribuição dos stakeholders para o desempenho; e, garantir que as medidas de desempenho sejam construídas a partir de uma fundamentação teórica mais robusta. De acordo com Kurien e Qureshi (2011), o Performance Prism possui uma visão mais abrangente dos interesses de diferentes stakeholders que a encontrada em outros modelos. Ainda segundo esses autores, esta estrutura, com a clara identificação dos stakeholders e suas necessidades antes do processo de medição iniciar, garante que a medição de desempenho tenha fundações fortes (KURIEN; QURESHI, 2011).

Um dos pontos fracos para o método do prisma são, segundo Kurien e Qureshi (2011) a sua baixa capacidade de fornecer informação sobre como as medidas de desempenho devem ser implementadas. Striteska e Spickova (2012) concordam com este ponto fraco e acrescentam outros, tais como a ineficiência de algumas medidas na prática e a existência de pouca lógica entre as medições, faltando conexões suficientes entre os resultados e os operadores.

\section{O SETOR SUCROENERGÉTICO NO BRASIL: INDICADORES DE DESEMPENHO EMPRESARIAIS E PRINCIPAIS CARACTERÍSTICAS}

O setor sucroenergético é responsável por mais de 900 mil empregos formais diretos e 70 mil produtores rurais de cana-de-açúcar independentes (UNIÃO DA INDÚSTRIA DE CANA-DE-AÇÚCAR [UNICA], 2019). No ano de 2017, foram geradas US\$ 12 bilhões em divisas externas com exportações de açúcar e etanol, tornando o setor sucroenergético o terceiro segmento na pauta de exportações do agronegócio no Brasil para aquele ano, atrás apenas do complexo soja e de carnes (MAPA, 2019b). Segundo o site da União das Indústrias de Cana-de-Açúcar (UNICA, 2019), o valor bruto movimentado pela cadeia sucroenergética supera os 
US $\$ 100$ bilhões, e contribui com US $\$ 43$ bilhões para o PIB brasileiro (cerca de $2 \%$ do total).

Os principais produtos obtidos a partir do processamento da cana-de-açúcar são o açúcar, o álcool (principalmente como etanol) e a energia obtida através da queima do bagaço e da palha. O Brasil é, atualmente, um dos maiores produtores e exportadores de açúcar no mundo, com 37 milhões de toneladas produzidas e 29 milhões de toneladas exportadas na safra de 2017/2018, que são quantias que correspondem a $20 \%$ da produção mundial e $40 \%$ do volume de exportação mundial desse produto (UNICA, 2019). Com relação à produção de etanol, o Brasil é o segundo maior produtor mundial, com 27 bilhões de litros produzidos na safra 2017/2018, sendo apenas superado pelos Estados Unidos. A fonte de cogeração a partir da biomassa gerou no ano de 2014, segundo o UNICA (2019), cerca de 20,8 GWh, o que representou $4 \%$ do consumo total do país, tornando-a a terceira fonte mais importante da matriz energética brasileira, atrás apenas da hídrica e da fóssil.

O processo de produção nas indústrias de cana-de-açúcar envolve diferentes áreas. Segundo os autores Paiva e Morabito (2007), o processo agroindustrial de produção de açúcar, álcool e subprodutos, pode ser dividido em três fases principais: fase agrícola (que envolve o plantio e tratos culturais), fase CCT (envolve a colheita da cana-de-açúcar, obtida através de Corte, Carregamento e Transporte da matéria-prima) e fase industrial (processamento da matéria-prima em produtos finais). Para todas as fases, existem decisões financeiras e não financeiras que devem ser tomadas para atender eficazmente às exigências da etapa e da empresa de forma global.

Brustein e Tomiya (1995) defendem que compreender o modelo econômico de uma usina sucroenergética é importante para que uma abordagem sistêmica do funcionamento do setor possa ser considerada. O fluxograma simplificado do processo agroindustrial de uma usina sucroenergética proposto por Brustein e Tomiya (1995) é apresentado na Figura 2. Nele, é possível identificar o processo produtivo da cana-de-açúcar dividido em duas fases principais: a Fase Agrícola, cujo produto final é a cana-de-açúcar, e a Fase Industrial, que produz açúcar, álcool, bagaço, energia e outros subprodutos. 
Figura 2 - Fluxograma simplificado do processo agroindustrial em usinas de cana-de-açúcar

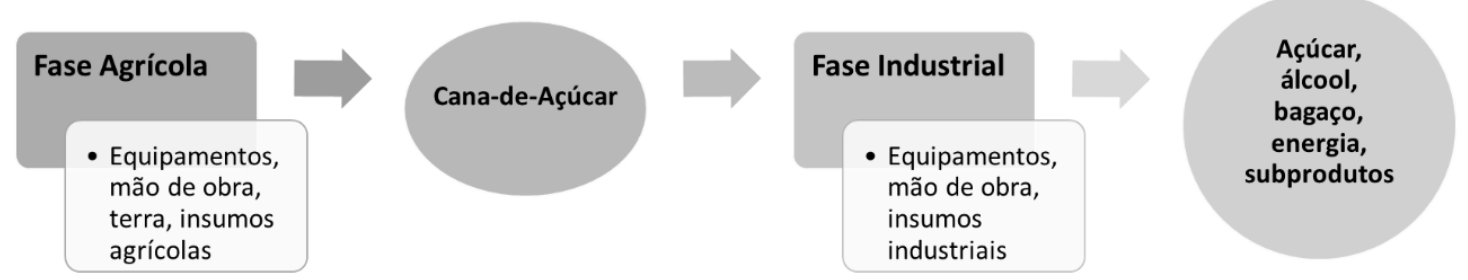

Fonte: Adaptado de Brunstein e Tomiya (1995).

A cana-de-açúcar se deteriora à medida que aumenta o tempo entre a colheita e a moagem, portanto, entre o corte da cana e a sua entrega na moenda para processamento, é necessário que os gestores coordenem as operações para manter a qualidade da matéria-prima, sem prejudicar o abastecimento. Tendo em vista a necessidade de rápido processamento da cana e das decisões que envolvem quais produtos e em que quantidades devem ser processados, é importante para as empresas do setor que exista um planejamento e controle da produção eficiente (SILVA; ALVES; COSTA, 2011; JUNQUEIRA, 2014).

De acordo com Brustein e Tomiya (1995), as decisões de caráter estratégico em uma usina são aquelas que alteram a estratégia inicial definida para uma safra e são tomadas, tipicamente, no começo da safra, definindo a estrutura física da usina. O nível tático refere-se a decisões tomadas para o médio prazo. Essas decisões estão associadas a políticas que estabelecem quais recursos a empresa utilizará (SCARPELLI, 2007). As decisões de caráter operacional nas usinas, segundo Brustein e Tomiya (1995), são as que administram a utilização de recursos e mãode-obra, com a suposição de que não ocorrerá alteração na estrutura física da empresa. Segundo Scarpelli (2007), as decisões de nível operacional da unidade de negócio, são consideradas decisões do dia-a-dia. Estas decisões têm como objetivo coordenar e permitir a execução das atividades necessárias para se concluir os propósitos da empresa.

Os autores Paiva e Morabito (2007) destacam que na área agrícola das usinas, são elaborados modelos de planejamento da colheita, de programação do transporte de cana, de distribuição e armazenagem de açúcar e álcool, de seleção de variedades de mudas e da programação da reforma do canavial. Na área industrial, os autores citam que os principais esforços são voltados para modelar o processo de produção de açúcar, álcool e subprodutos. 
Esta modelagem de processos e operações, seja na parte agrícola ou na industrial, é fundamental para a construção de indicadores adequados à gestão de empresas do agronegócio.

Estes modelos têm permitido estudos de diversos autores sobre indicadores de desempenho aplicados a empresas do agronegócio brasileiras (CALLADO; CALLADO; ALMEIDA, 2007a, 2007b; MENDES; TEIXEIRA, 2009; PELOIA; MILAN, 2010; ANDIA; GARCIA; BACHA, 2011; ROSADO JUNIOR et al., 2011; CARDOSO, 2012; MARQUES, 2012; CRUZ, 2013; OAIGEN et al., 2013; JUNQUEIRA, 2014; PANTOJA; SAMANEZ; CASTRO; AIUBE, 2016; ARTUZO; FOGUESATO; SOUZA; SILVA, 2018). Muitas empresas do agronegócio estão procurando profissionalizar suas estratégias de negócio e buscam intensificar o uso de sistemas de medição e controle usando os métodos que melhor se adaptam ao perfil de seu setor (ROSADO JUNIOR et al., 2011).

Os indicadores de desempenho apresentados no Quadro 1 foram identificados na literatura e são classificados de acordo com a etapa produtiva das usinas do setor sucroenergético em que são usados. As etapas foram separadas em Indústria, Financeira/Administrativa e Agrícola/CCT.

\begin{tabular}{|c|c|c|}
\hline Indicador & Área de Aplicação & Autores \\
\hline Estoque de Produto Acabado & \multirow{6}{*}{ Indústria } & Paiva e Morabito, 2007 \\
\hline Produção por Produto & & \multirow{3}{*}{ Silva, 2009} \\
\hline $\begin{array}{l}\text { Rendimentos dos Processos } \\
\text { Industriais (por etapa e total) }\end{array}$ & & \\
\hline Capacidade da Moenda & & \\
\hline$\%$ Pol & & \multirow[b]{2}{*}{ Lima, 2009} \\
\hline $\begin{array}{l}\text { \% Pureza (Pol/Brix) } \\
\% \text { Fibra }\end{array}$ & & \\
\hline Assiduidade & \multirow{5}{*}{$\begin{array}{l}\text { Financeiro / } \\
\text { Administrativo }\end{array}$} & \multirow{3}{*}{$\begin{array}{l}\text { Brunstein e Tomiya, } \\
1995 \\
\text { Brunstein e Tomiya, } \\
\text { 1995; Pantoja et al., } \\
2016\end{array}$} \\
\hline Principais Taxas do Mercado & & \\
\hline $\begin{array}{l}\text { Modelo Econômico de Custos e } \\
\text { Receitas por setor }\end{array}$ & & \\
\hline $\begin{array}{l}\text { Atendimento às Tributações } \\
\text { Governamentais }\end{array}$ & & Pantoja et al., 2016 \\
\hline Qualidade do Serviço de Terceiros & & $\begin{array}{l}\text { Lütkemeyer Filho et al., } \\
2015\end{array}$ \\
\hline $\begin{array}{l}\text { Quantidade de Frentes de Corte } \\
\text { Distância Média por Frente } \\
\text { Tempo de Ciclo de Viagem }\end{array}$ & Agrícola / CCT & $\begin{array}{l}\text { Peloia e Milan, 2010; } \\
\text { Silva et al., } 2011\end{array}$ \\
\hline
\end{tabular}


Quadro 1 - Indicadores encontrados na literatura usados no setor sucroenergético e suas áreas de

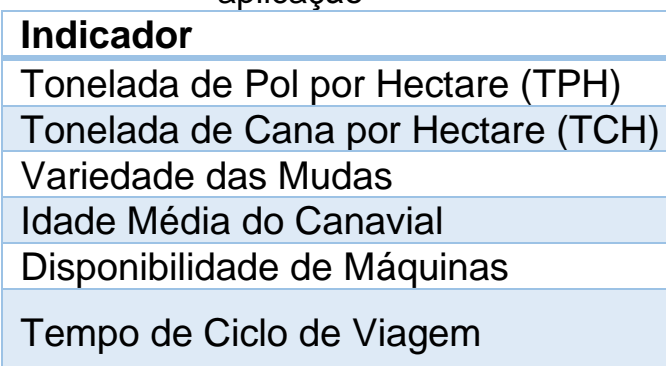

Pol: Quantidade em peso de sacarose contida em $100 \mathrm{ml}$ de solução; Brix: Percentagem aparente de sólidos solúveis contidos em uma solução açucarada impura; TPH: Toneladas de Pol por Hectare; TCH: Toneladas de Cana por Hectare; CCT: Corte, Carregamento e Transbordo.

Fonte: Autores (2019).

\section{PROCEDIMENTOS METODOLÓGICOS}

Esta pesquisa busca resolver um problema encontrado no mundo real, o que a caracteriza como de natureza aplicada (NAPPI, 2014). O presente trabalho está inserido na área de pesquisas de gestão de operações, e tem como objetivo gerar conhecimento tanto para a comunidade acadêmica quanto para o ambiente empresarial.

A abordagem desta pesquisa é qualitativa. Esta abordagem tende a ser menos estruturada, pois, assim, pode captar perspectivas e interpretações distintas das pessoas envolvidas na pesquisa (MARTINS, 2012a). Os diversos pontos de vista podem se complementar, mas também podem divergir.

O método de pesquisa utilizado foi o da pesquisa-ação. A pesquisa-ação, um dos métodos qualitativos para abordagem de problemas, é uma pesquisa social com base empírica, na qual pesquisadores e participantes estão envolvidos de modo cooperativo ou participativo e ela é concebida e realizada em associação com uma ação ou com a resolução de um problema coletivo (TURRIONI; MELLO, 2012).

Turrioni e Mello (2012) consideram a pesquisa-ação como um processo cíclico com cinco passos: planejar a pesquisa-ação, coletar dados, analisar dados e planejar a ação, implementar ações e avaliar resultados e gerar relatório. Esses autores incluem um monitoramento constante em todas as etapas do processo, conforme mostrado na Figura 3. 


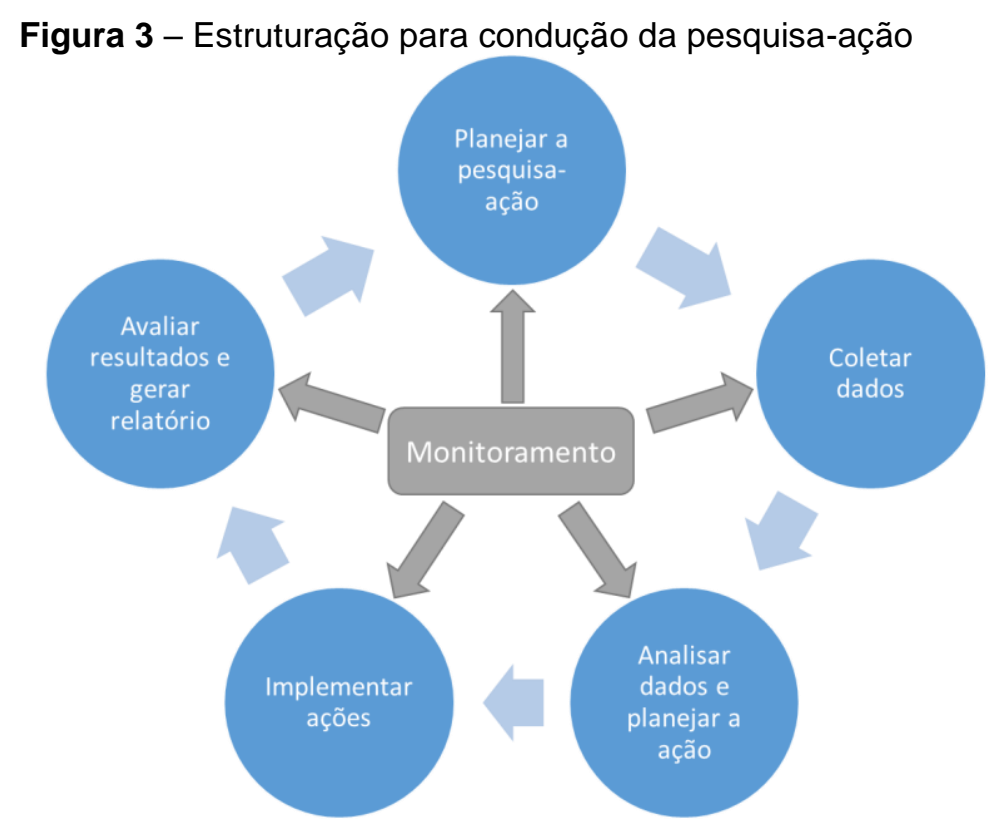

Fonte: Adaptado de Turrioni e Mello (2012).

A unidade onde foi desenvolvida a pesquisa-ação é uma usina de cana-deaçúcar, localizada na região de Pirassununga - SP. Ela produz açúcar, álcool, levedura e faz cogeração de energia elétrica, com capacidade de moagem de 3.100.000 toneladas de cana por safra. Internamente, ela possui quatro áreas: indústria, agrícola, manutenção automotiva e administrativa. Hierarquicamente, é formada por um comitê diretivo composto por quatro diretores. Os diretores estão envolvidos, via comitê, diretamente em todas as áreas da usina. Abaixo dos diretores, na hierarquia desta usina, estão os gerentes de área. Cada um destes gerencia supervisores em subáreas. São nove gerentes e um supervisor que respondem diretamente ao comitê diretivo.

A técnica usada para coletar dados foi a de entrevistas não estruturadas com a equipe de gestores (protocolo da pesquisa-ação). Participaram do processo oito gerentes de área e dois supervisores, ou seja, toda a equipe gerencial da empresa. Esta equipe participou de todas as etapas da pesquisa, com várias interações com a equipe de pesquisadores. As entrevistas foram feitas com seis questões abertas, referentes aos indicadores de desempenho usados na área do entrevistado. As perguntas foram:

1. Na disposição hierárquica da usina, quais os principais indicadores (resultados) são cobrados de você? 
2. Como as informações dos indicadores são obtidos e apresentados para os superiores?

3. Na disposição hierárquica da usina, quais os principais indicadores (resultados) você cobra da sua equipe?

4. Como as informações dos indicadores são obtidas e apresentadas para você?

5. Entre os indicadores constantes do plano de metas da usina, você consegue classificar em nível de importância?

6. Como são definidos os valores dos indicadores do plano de metas da usina?

Com estas entrevistas, foi possível obter, para cada gestor, quais são os indicadores da área de atuação deles mais importantes e de qual fonte de dados as informações são extraídas para se obter os valores dos indicadores. Em geral, os indicadores são extraídos a partir de consulta a um dos softwares de gestão usados nas áreas.

Após as entrevistas, foram tabelados todos os indicadores constantes do plano de metas e indicadores obtidos através de conversas com os gestores de área. Foram coletadas informações de indicadores que não fazem parte do plano de metas, mas são importantes para os gestores e todos os indicadores foram classificados a partir de informações obtidas nas entrevistas.

\section{APRESENTAÇÃO E ANÁLISE DOS RESULTADOS}

A análise documental identificou que a empresa dispunha de um manual (plano de metas) com diversos indicadores de desempenhos, separados por área, com metas a serem atingidas para bonificação da equipe. No plano de metas da usina eram utilizados e descritos 194 indicadores de desempenho (dentre estes, muitos repetidos aplicados em áreas distintas), com o valor alvo a ser atingido e quais bonificações (remuneração extra em termos de percentual de salário) podem gerar para os colaboradores da área. Os indicadores propostos pela pesquisa se apropriaram de alguns destes indicadores. 
Os indicadores resultantes da pesquisa e propostos para a usina são classificados como estratégicos (visão de longo prazo) e táticos (visão de médio prazo). Indicadores operacionais (curto prazo) não estão contemplados neste modelo. Vale lembrar que os indicadores foram deliberadamente idealizados para servirem a decisões de médio e longo prazos.

Para cada uma das perspectivas do Performance Prism foram definidos, em parceria entre o pesquisador e a equipe da usina, dois ou mais objetivos para auxiliar na classificação dos indicadores propostos. A questão proposta para a perspectiva "Satisfação dos Stakeholders" pode ser respondida com indicadores que tenham por objetivo atender os contratos firmados com os clientes e indicadores que tenham por objetivo atender os demais stakeholders. A questão da perspectiva "Estratégias" pode ser respondida com indicadores dos resultados financeiros e indicadores de redução de custos. Para a perspectiva de "Processos" do Performance Prism, os objetivos atendidos pelos indicadores são os de eficiência industrial, os que indicam a relação entre o produto final e a matéria prima utilizada (cana-de-açúcar) e os que detalham a gestão de processos internos. A questão da perspectiva "Capacidades" pode ser respondida com indicadores de motivação da equipe e indicadores de controle de ativos. Por fim, a pergunta da perspectiva da "Contribuição dos Stakeholders" pode ser respondida com indicadores de contribuição de stakeholders internos e externos à empresa. Os objetivos propostos estão resumidos na Figura 4. A partir destes objetivos foi construído um primeiro conjunto de indicadores de desempenho que atendem à visão global da usina, usando indicadores do plano de metas e obtidos a partir de entrevistas.

Após percorrer todos os ciclos da pesquisa-ação (figura 3), uma segunda rodada foi iniciada para refinar os indicadores propostos e todos os ciclos da pesquisa-ação foram percorridos novamente. Segundo a equipe de gestores da usina, o número de indicadores propostos inicialmente era muito elevado e, por este motivo não atendia as necessidades da diretoria da empresa.

Em uma nova proposta, alguns indicadores foram agrupados e a quantidade final foi reduzida. Este procedimento foi realizado em novas reuniões com os gerentes envolvidos no processo. Os indicadores propostos com as alterações solicitadas estão apresentados no Quadro 2. Esta foi a proposta final de indicadores proposto por esta pesquisa à Usina. Como a pesquisa-ação é desenvolvida em 
ciclos, a usina pode implementar outros ciclos para aprimorar ainda mais o seu conjunto de indicadores.

Figura 4 - Objetivos definidos em conjunto com a equipe da usina para a classificação dos indicadores selecionados nas perspectivas do performance prism

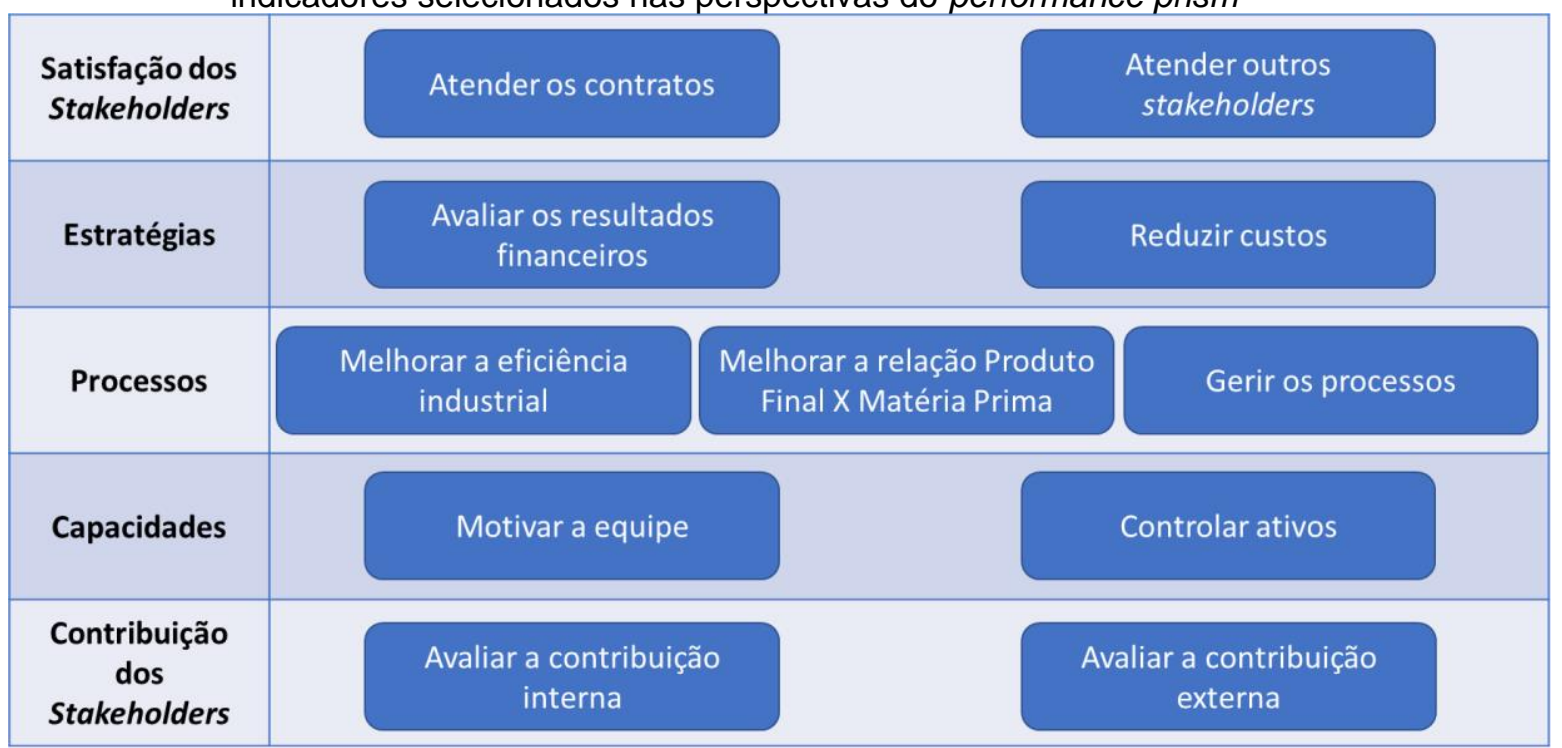

Fonte: Autores (2019).

Todos os indicadores selecionados são apresentados no Quadro 2, com as seguintes informações:

- Perspectiva do Performance Prism: Qual das perspectivas deste framework o indicador atende (Satisfação do Stakeholder, Estratégia, Processo, Capacidade ou Contribuição do Stakeholder);

- Objetivo: Qual dos objetivos propostos na Figura 4 é atendido pelo indicador;

- Indicador: Nome do indicador selecionado;

- Origem: Se o indicador foi selecionado a partir do plano de metas da usina ou se foi selecionado a partir de entrevista com os gestores;

- Literatura: Se este indicador já foi encontrado em alguma literatura pesquisada, quais os autores da pesquisa em que o indicador foi citado;

- Tipo: Se o indicador é do tipo Estratégico ou Tático. 


\section{CONSIDERAÇÕES FINAIS}

Os resultados encontrados mostram a importância para empresas agroindustriais da construção de indicadores de desempenho que considerem de forma interdependente os processos de produção agropecuária e industrial. $O$ processo metodológico envolvido nesta pesquisa, a chamada pesquisa-ação, obviamente não permite generalizar este achado para o conjunto de agroindústrias existentes. No entanto, ele permitiu, através de várias, diversificadas e longas interações com uma equipe gerencial muito experiente, verificar empiricamente esta afirmação no caso estudado. Segundo estes gestores, ignorar ou avaliar de forma inadequada o que acontecia no campo significaria tomar decisões equivocadas na indústria e vice-versa. Neste sentido, uma das hipóteses centrais da pesquisa foi comprovada para o caso estudado. O conjunto de indicadores desenvolvidos e que passou a ser utilizado pela empresa é a prova cabal desta afirmação.

Vários dos indicadores propostos não estavam entre os 194 indicadores existentes no início da pesquisa. Este fato revela três coisas. A primeira é que alguns indicadores julgados importantes estavam ausentes deste conjunto enorme de informações. A segunda, segundo a própria direção da empresa, é que um conjunto tão grande de indicadores inviabiliza a utilização prática do sistema. $\mathrm{O}$ excesso de informações pode ser tão ruim quanto a ausência de informações. $O$ terceiro ponto é que pode haver desperdício de recursos na elaboração de indicadores que não tem utilidade efetiva no auxílio à tomada de decisão. 
Quadro 2 - Proposta final de conjunto de indicadores

\begin{tabular}{|c|c|c|c|c|c|}
\hline Objetivos & № & Indicadores & Origem & Literatura & Tipo \\
\hline \multicolumn{6}{|c|}{ Satisfação dos Stakeholders } \\
\hline $\begin{array}{c}\text { Atender aos } \\
\text { contratos }\end{array}$ & 1 & $\begin{array}{l}\text { Qualidade e Quantidade de produto final } \\
\text { entregue }\end{array}$ & Entrevistas com gestores & Silva, 2009; Lima, 2009 & Estratégico \\
\hline \multirow{2}{*}{$\begin{array}{c}\text { Atender outros } \\
\text { Stakeholders }\end{array}$} & 2 & $\%$ de atendimento às legislações ambientais & Entrevistas com gestores & Pantoja et al., 2016 & Estratégico \\
\hline & 3 & $\%$ satisfação do cliente interno & Entrevistas com gestores & & Tático \\
\hline \multicolumn{6}{|c|}{ Estratégias } \\
\hline \multirow{3}{*}{$\begin{array}{l}\text { Avaliar os resultados } \\
\text { financeiros }\end{array}$} & 4 & Ebitda / Faturamento & Plano de metas da usina & Brunstein e Tomiya, 1995 & Estratégico \\
\hline & 5 & \% negociações bem sucedidas (Consecana) & Entrevistas com gestores & \begin{tabular}{|l|} 
Brunstein e Tomiya, 1995; \\
Pantoja et al., 2016
\end{tabular} & Estratégico \\
\hline & 6 & Metas de taxas do mercado & Entrevistas com gestores & Brunstein e Tomiya, 1995 & Estratégico \\
\hline \multirow{2}{*}{ Reduzir custos } & 7 & $\%$ de economia no orçamento & Plano de metas da usina & Silva, 2009 & Estratégico \\
\hline & 8 & Custos / tonelada & Plano de metas da usina & Brunstein e Tomiya, 1995 & Tático \\
\hline \multicolumn{6}{|c|}{ Processos } \\
\hline \multirow{2}{*}{$\begin{array}{l}\text { Melhorar a eficiência } \\
\text { industrial }\end{array}$} & 9 & Rendimento dos processos industriais & Plano de metas da usina & Silva, 2009 & Tático \\
\hline & 10 & $\begin{array}{l}\text { \% moagem de cana (capacidade utilizada / } \\
\text { total da moenda) }\end{array}$ & Plano de metas da usina & Costa e Moll, 1999 & Tático \\
\hline \multirow{3}{*}{$\begin{array}{l}\text { Melhorar a relação } \\
\text { Produto Final x } \\
\text { Matéria Prima }\end{array}$} & 11 & $\%$ área plantada & Plano de metas da usina & Costa e Moll, 1999 & Estratégico \\
\hline & 12 & TCH e TPH & Entrevistas com gestores & Costa e Moll, 1999 & Estratégico \\
\hline & 13 & $\%$ área realizada de tratos culturais & Plano de metas da usina & Costa e Moll, 1999 & Tático \\
\hline \multirow[b]{2}{*}{ Gerir os processos } & 14 & $\%$ consumo de combustível & Plano de metas da usina & & Tático \\
\hline & 15 & Controle de estoques & Plano de metas da usina & $\begin{array}{l}\text { Paiva e Morabito, 2007; } \\
\text { Silva et al., } 2011\end{array}$ & Tático \\
\hline \multicolumn{6}{|c|}{ Capacidades } \\
\hline \multirow{2}{*}{ Motivar a equipe } & 16 & $\%$ retenção de funcionários & Entrevistas com gestores & Brunstein e Tomiya, 1995 & Tático \\
\hline & 17 & Horas extras não programadas & Plano de metas da usina & Silva et al., 2011 & Tático \\
\hline \multirow{3}{*}{ Controlar ativos } & 18 & $\%$ reformas (maquinário, equipamentos) & Plano de metas da usina & Brunstein e Tomiya, 1995 & Tático \\
\hline & 19 & $\%$ disponibilidade & Plano de metas da usina & Iannoni e Morabito, 2002 & Tático \\
\hline & 20 & $\%$ renovação de ativos & Entrevistas com gestores & & Estratégico \\
\hline \multicolumn{6}{|c|}{ Contribuição dos Stakeholders } \\
\hline \multirow{3}{*}{$\begin{array}{l}\text { Avaliar contribuição } \\
\text { interna }\end{array}$} & 21 & Início da safra & Plano de metas da usina & & Tático \\
\hline & 22 & $\%$ assiduidade & Entrevistas com gestores & Brunstein e Tomiya, 1995 & Tático \\
\hline & 23 & $\%$ atendimento ao programa $5 \mathrm{~S}$ & Plano de metas da usina & & Tático \\
\hline $\begin{array}{c}\text { Avaliar contribuição } \\
\text { externa }\end{array}$ & 24 & Qualidade dos fornecedores & Plano de metas da usina & $\begin{array}{l}\text { Lütkemeyer Filho et al., } \\
2015\end{array}$ & Estratégico \\
\hline
\end{tabular}

Fonte: Autores (2019).

As perspectivas do Performance Prism foram úteis ao estabelecimento de objetivos que redundaram nos indicadores propostos. Este exercício permitiu a construção de 24 indicadores que permitirão aos stakeholders acompanhar a evolução da empresa e tomar decisões estratégicas e operacionais adequadas aos objetivos pretendidos.

Este trabalho possui como resultado um conjunto de indicadores de desempenho que atende às expectativas de gerenciamento estratégico e tático de uma usina de cana-de-açúcar. Como os processos produtivo e gerencial dessas empresas são complexos, este conjunto deve responder ao desafio de contemplar todas as áreas da empresa (agrícola, industrial, de manutenção automotiva e 
administrativa), sem gerar uma quantidade de indicadores que extrapole, em número, as capacidades cognitivas e interpretativas de diretores e gerentes, usuários principais do sistema proposto. Assim, os indicadores propostos atêm-se às informações necessárias a uma visão sistêmica e global da empresa, sem que indicadores operacionais, necessariamente mais detalhados e em maior número, tenham sido objetos da proposta do modelo desenvolvido nesta dissertação. $O$ conjunto elaborado nesta pesquisa consta de 24 indicadores que abrangem as áreas de uma usina de açúcar citadas acima e as intersecções entre elas.

Para a equipe de gestores da usina que participaram da pesquisa, os indicadores propostos atendem às necessidades de gestão da empresa para os diretores. Para os demais níveis hierárquicos da empresa, de gerentes, supervisores, este trabalho sugere que os ciclos de pesquisa-ação aqui descritos sejam replicados pela equipe.

A principal limitação deste trabalho está relacionada ao procedimento técnico da pesquisa-ação e às especificidades da usina estudada. Os resultados aqui apresentados são importantes e úteis para esta usina específica. Para outra usina, devido a características distintas de gestão, possivelmente outros indicadores são tão ou mais importantes que os aqui apresentados. Para se obter um conjunto de indicadores para outra usina, seria necessário seguir novamente os passos da pesquisa-ação, com entrevistas a gestores e análise de informações utilizadas.

Como consequência das limitações apresentadas, futuros trabalhos podem seguir os passos aqui propostos da pesquisa-ação, para criar conjuntos de indicadores de desempenho que atendam a outras usinas do setor sucroenergético. Futuras pesquisas também podem seguir os passos para criar um framework que atenda empresas de outros setores dentro ou fora do agronegócio. Em ambos os casos, o método da pesquisa-ação é recomendado, pois o pesquisador pode atuar como um facilitador no desenvolvimento e possível implantação do conjunto de indicadores.

Finalmente, para a usina estudada, fica proposta a sugestão de seguir executando os ciclos da pesquisa-ação aqui apresentados para implantação dos indicadores em um sistema de informação. Com o uso do mesmo método, é sugerida, também, a criação de níveis de indicadores para gerência e supervisão na 
forma de desdobramento de indicadores, tendo como base o conjunto proposto para o comitê diretivo.

\section{REFERÊNCIAS}

ANDIA, L. H.; GARCIA, R.; BACHA, C. J. C. A Influência dos Fatores Econômicos e Jurídicos sobre o Desempenho das Empresas do Agronegócio Brasileiro - Período de 2003 a 2005. Revista de Economia e Sociologia Rural, Piracicaba, SP, v.49, n.4, p.875-908, out./dez., 2011. https://doi.org/10.1590/S0103-20032011000400004

ARTUZO, F. D.; FOGUESATTO, C. R.; SOUZA, A. R. L.; SILVA, L. X. Gestão de Custos na Produção de Milho e Soja. Revista Brasileira de Gestão e Negócios, São Paulo, v.20, n.2, p.273-294, abr./jun., 2018.

BATALHA, M. O.; SILVA, A. L. Gerenciamento de Sistemas Agroindustriais: Definições, Especificidades e Correntes Mercadológicas. In: BATALHA, M. O. (coord.), Gestão Agroindustrial. 3. ed., v.1, São Paulo: Atlas, p.1-62, 2007.

BITITCI, U.S.; BOURNE, M.; CROSS, J.A.F.; NUDURUPATI, S.S.; SANG, K. Editorial: towards a theoretical foundation for performance measurement and management. International Journal of Management Reviews, v. 20, p. 653-660, 2018. https://doi.org/10.1111/ijmr.12185

BRUNSTEIN, I.; TOMIYA, E. H. Modelo Econômico de Empresa Sucroalcooleira. Gestão \& Produção, São Carlos, v. 2, n. 3, p. 264-280, dez. 1995. https://doi.org/10.1590/S0104$\underline{530 \times 1995000300003}$

CALLADO, A. L. C.; CALLADO, A. A. C.; ALMEIDA, M. A. A Utilização de Indicadores Gerenciais de Desempenho Industrial no Âmbito de Agroindústrias. Revista Eletrônica Sistemas \& Gestão, v. 2, n. 2, p.102-118, mai./ago. 2007a.

CALLADO, A. L. C.; CALLADO, A. A. C.; ALMEIDA, M. A. Análise dos indicadores e ações de organizações agroindustriais segundo as perspectivas do balanced scorecard. Revista Universo Contábil, v. 3, n. 3, p.38-53, set./dez., 2007b.

CANIATO, F.; DORAN, D.; SOUSA, R.; BOER, H. Designing and developing om research from concept to publication. International Journal of Operations \& Production Management, v. 38, n. 9, p.1 836-1856, 2018. https://doi.org/10.1108//JOPM-01-2017-0038

CARDOSO, M. Percepção das empresas de lácteos sobre programas de pagamento por qualidade do leite e evolução dos indicadores de qualidade higiênico-sanitário. 2012. 57P. Dissertação (Mestrado Profissional em Ciência e Tecnologia do Leite e Derivados) - Universidade Federal de Juiz de Fora, Juiz de Fora, 2012.

COSTA, H. G.; MOLL, R. N. Emprego de Método de Análise Hierárquica (AHP) na Seleção de Variedades para o Plantio de Cana-de-açúcar. Gestão \& Produção, São Carlos, v. 6, n. 3, p. 243-256, dez. 1999. https://doi.org/10.1590/S0104-530X1999000300009

COUGHLAN, P.; COUGHLAN, D. Action Research. In: KARLSSON, C (ed.). Researching Operations Management, 1 ed., New York, USA and London UK: Routledge, p. 236-264, 2009. 
CRUZ, A. A. Indicadores de Sustentabilidade: estudo de caso em propriedades produtoras de leite nas regiões sul e sudeste do Brasil Utilizando a Metodologia RISE. 2013. 108P. Dissertação (Mestrado em Ciências - Economia Aplicada) - Universidade de São Paulo, Escola Superior de Agricultura “Luiz de Queiroz", Piracicaba, 2013.

FERREIRA, A. L. Demanda e conservação de óleo diesel na fase agrícola do proálcool. 1992. 119p. Dissertação (Mestrado em Planejamento de Sistemas Energéticos) -

Universidade Estadual de Campinas, Faculdade de Engenharia Mecânica, Campinas (SP), 1992.

FERREIRA, J. O.; BATALHA, M. O. ; DOMINGOS, J. C. Integrated Planning Model for Citrus Agribusiness System Using Systems Dynamics. Computer and Electronics in Agriculture, v. 126, p.1-11, ago. 2016. https://doi.org/10.1016/j.compag.2016.04.029

FISCHER, A. L. Impactos sociais do proálcool: um estudo sobre as relações, o processo e as condições de trabalho na agroindústria canavieira paulista. 1992. 254p. Dissertação (Mestrado em Ciências Sociais). Pontifícia Universidade Católica de São Paulo, São Paulo (SP), 1992.

IANNONI, A. P.; MORABITO, R. Análise do sistema logístico de recepção de cana-deaçúcar: um estudo de caso utilizando simulação discreta. Gestão \& Produção, São Carlos, v.9, n.2, p.107-128, ago., 2002. https://doi.org/10.1590/S0104-530X2002000200002

JUNQUEIRA, R. A. R. Programação das frentes de colheita de cana-de-açúcar: uma modelagem visando o equilíbrio das capacidades de colheita e transporte. 2014. 257p. Tese (Doutorado em Engenharia de Produção) - Universidade Federal de São Carlos - UFSCar, São Carlos, 2014.

KAPLAN, R. S.; NORTON, D. P. A estratégia em ação: balanced scorecard. rio de janeiro: Editora Campus - Elsevier, 1997.

KAPLAN, R. S.; NORTON, D. P. The balanced scorecard: measures that drive performance. Harvard Business Review, p. 71-79, jan./fev. 1992.

KURIEN, G. P.; QURESHI, M. N. Study of performance measurement practices in supply chain management. International Journal of Business, Management and Social Sciences, v. 2, n. 4, p.19-34, 2011.

LIMA, A. D. Otimização do aproveitamento do palhiço da cana-de-açúcar. 2009. 93p. Tese (Doutorado em Agronomia - Energia na Agricultura) - Faculdade de Ciências Agronômicas, Universidade Estadual Paulista, Campus de Botucatu, Botucatu, 2009.

LÜTKEMEYER FILHO, M.G.; VACCARO, G.L.R.; FREITAS, E.C. Identificação dos fatores de satisfação de clientes em serviços: um estudo em concessionárias do agronegócio.

Revista Brasileira de Gestão e Negócios, São Paulo, v.17, n. 58, p.1408-1425, out./dez. 2015. https://doi.org/10.7819/rbgn.v17i58.1946

LYNCH, R.; CROSS, K. Measure Up! yardsticks for continuous improvement. Basil Blackwell Inc, Cambridge, MA, 1991.

MARQUES, I. C. Mapas estratégicos para modelos de gestão voltados a competitividade da cadeia produtiva do frango de corte: um estudo na microrregião de Anápolis - GO. 2012. 146p. Dissertação (Mestrado em Agronegócio - Competitividade e Gestão do Agronegócio) - Universidade Federal de Goiás, Goiânia, 2012. 
MARTINS, R. A. Abordagens quantitativa e qualitativa. In: CAUCHICK MIGUEL, P. A. (org), Metodologia de pesquisa em engenharia de produção e gestão de operações. Rio de Janeiro: Elsevier, p. 47-63, 2012a.

MARTINS, R. A. Princípios da pesquisa científica. In: CAUCHICK MIGUEL, P. A. (org). Metodologia de pesquisa em engenharia de produção e gestão de operações. Rio de Janeiro: Elsevier, p.7-31, 2012b.

MASIERO, G.; LOPES, H. Etanol e biodiesel como recursos energéticos alternativos: perspectivas da América Latina e da Ásia. Revista Brasileira de Política Internacional, v.51, n.2, p.60-79, 2008. https://doi.org/10.1590/S0034-73292008000200005

MENDES, C. I. C.; TEIXEIRA, S. R. Controle da Produção Leiteira e a Demanda por Sistemas Computacionais Simples. In: CONGRESSO BRASILEIRO DE

AGROINFORMÁTICA, 7., 2009, Viçosa, MG: UFV. [Anais...]. Viçosa, MG: UFV, 2009. Não paginado. SBIAgro 2009.

MINISTÉRIO DA AGRICULTURA, PECUÁRIA E ABASTECIMENTO [MAPA]. Estatísticas e Dados Básicos de Economia Agrícola - Novembro/2018. 2019. Disponível em:

http://www.agricultura.gov.br/assuntos/politica-agricola/todas-publicacoes-de-politicaagricola/estatisticas-e-dados-basicos-de-economiaagricola/copy of PASTADENOVEMBRO2018.pdf. Acesso em: 21 jan. 2019a.

MINISTÉRIO DA AGRICULTURA, PECUÁRIA E ABASTECIMENTO [MAPA]. Exportações do Agro em Alta de Quase 6\% Ultrapassam US\$ 100 bilhões. 2019. Disponível em: http://www.agricultura.gov.br/noticias/exportacoes-do-agro-em-alta-de-quase-6-ultrapassamus-100-bi. Acesso em: 21 jan. 2019b.

MOURA, M.F. Gestão de custos interorganizacionais para o gerenciamento dos custos totais: estudo de caso em uma usina de cana-de-açúcar na Região do Triângulo Mineiro MG. 2014. 102p. Dissertação (Mestrado em Ciências Contábeis) - Faculdade de Ciências Contábeis da Universidade Federal de Uberlândia, Uberlândia, 2014.

NAPPI, V. Framework para desenvolver um sistema de medição de desempenho para PLM (Product Lifecycle Management) com indicadores de sustentabilidade, 2014. 316 p. Dissertação (Mestrado em Engenharia de Produção) - Escola de Engenharia de São Carlos da Universidade de São Paulo, São Carlos, 2014.

NEELY, A.; ADAMS, C.; CROWE, P. The performance prism in practice. Measuring Business Excellence, v. 5, n. 2, p. 6-13, 2001. https://doi.org/10.1108/13683040110385142

NEELY, A.; ADAMS, C. Perspectives on performance: the performance prism. Cranfield: University of Cranfield, 2000. Disponível em: http://www.som.cranfield.ac.uk/som/dinamiccontent/research/cbp/prismarticle.pdf. Acesso em: 24 ago. 2015.

NEELY, A.; GREGORY, M.; PLATTS, K. Performance measurement system design. a literature review and research agenda. International Journal of Operations \& Production Management, v. 15, n. 4, p.80-116, 1995. https://doi.org/10.1108/01443579510083622

NILSSON, F.; OLVE, N-G. Control systems in multibusiness companies: from performance management to strategic management. European Management Journal, v.19, n. 4, p.344358, ago. 2001. https://doi.org/10.1016/S0263-2373(01)00036-6 
OAIGEN, R. P.; BARCELLOS, J. O. J.; CANOZZI, M. E. A.; SOARES, J. C. R.; CANELLAS, L. C.; ALVES, C. O.; TAVARES, H. R.; COSTA, F. M. Competitividade inter-regional de sistemas de produção de bovinocultura de corte. Ciência Rural, Santa Maria, v. 43, n.8, p.1489-1495, ago. 2013. https://doi.org/10.1590/S0103-84782013000800024

ORELLANO, V. F.; SOUZA, A. D. N.; AZEVEDO, P. F. Elasticidade-preço da demanda por etanol no Brasil: como renda e preços relativos explicam diferenças entre Estados. Revista de Economia e Sociologia Rural, Piracicaba (SP), v. 51, n. 4, p. 699-718, out./dez. 2013. https://doi.org/10.1590/S0103-20032013000400005

PAIVA, R. P. O.; MORABITO, R. Um modelo de otimização para o planejamento agregado da produção em usinas de açúcar e álcool. Gestão \& Produção, São Carlos, v.14, n.1, p. 25-41, jan./abr. 2007. https://doi.org/10.1590/S0104-530X2007000100004

PANTOJA, D.E.L.; SAMANEZ, C.P.M.; CASTRO, J.G.; AIUBE, F.A.L. Valoração econômica da flexibilidade de produção em diferentes regiões do setor sucroalcooleiro brasileiro.

Revista Brasileira de Gestão e Negócios, São Paulo, v. 18, n. 60, p. 226-244, abr./jun. 2016.

PELOIA, P. R.; MILAN, M. Proposta de um sistema de medição de desempenho aplicado à mecanização agrícola. Revista Engenharia Agrícola, Jaboticabal, v. 30, n. 4, p. 681-691, jul./ago. 2010. https://doi.org/10.1590/S0100-69162010000400012

ROSADO JUNIOR, A. G.; LOBATO, J. F. P.; MÜLLER, C. Building consolidated performance indicators for an agribusiness company: a case study. Revista Brasileira de Zootecnia, v.40, n.2, p. 454-461, fev. 2011. https://doi.org/10.1590/S1516$\underline{35982011000200030}$

SCARPELLI, M. Planejamento e controle da produção. In: BATALHA, M. O. (coord.), Gestão Agroindustrial. 3. ed. v.1. São Paulo: Atlas, p. 336-430, 2007.

SCHENBERG, A. C. G. Biotecnologia e Desenvolvimento Sustentável. Estudos Avançados, São Paulo (SP), v. 24, n. 70, p. 7-17, 2010. https://doi.org/10.1590/S0103$\underline{40142010000300002}$

SILVA, A. F. Modelagem do planejamento agregado da produção de uma usina sucroalcooleira. 2009. 93p. Dissertação (Mestrado em Ciências da Engenharia da Produção) - Departamento de Engenharia de Produção, Universidade Federal de Itajubá, Itajubá, 2009.

SILVA, A. T. B.; SPERS, R. G.; WRIGHT, J. T. C.; COSTA, P. R. Cenários Prospectivos para o Comércio Internacional de Etanol em 2020. Revista de Administração, São Paulo (SP), v. 48, n. 4, p. 727-738, out./dez. 2013. https://doi.org/10.5700/rausp1117

SILVA, J. E. A. R.; ALVES, M. R. P. A.; COSTA, M. A. B. Planejamento de turnos de trabalho: uma abordagem no setor sucroalcooleiro com uso de simulação discreta. Gestão \& Produção, São Carlos, v.18, n.1, p. 73-90, 2011. https://doi.org/10.1590/S0104$\underline{530 \times 2011000100006}$

SMITH, M.; BITITCI, U. S. Interplay Between Performance Measurement and Management, Employee Engagement and Performance. International Journal of Operations \&

Production Management, v. 37, n. 9, p.1207-1228, 2017. https://doi.org/10.1108/IJOPM-06$\underline{2015-0313}$ 
STRITESKA, M.; SPICKOVA, M. Review and comparison of performance measurement systems. Journal of Organizational Management Studies, v. 2012, p.1-12, 2012.

https://doi.org/10.5171/2012.114900

TANGEN, S. Evaluation and revision of performance measurement systems. 2004. 213p. Tese (Doutorado em Engenharia da Produção) - Department of Production Engineering, Royal Institute of Technology, Stockholm, Sweden, 2004.

TURRIONI, J. B.; MELLO, C. H. P. Pesquisa-ação na engenharia de produção. In: CAUCHICK MIGUEL, P. A. (org). Metodologia de pesquisa em engenharia de produção e gestão de operações. Rio de Janeiro: Elsevier, p.149-167, 2012.

UNIÃO DA INDÚSTRIA DE CANA-DE-AÇÚCAR [UNICA]. Disponível em: http://www.unica.com.br/. Acesso em: 07 jan. 2019.

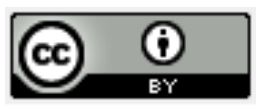

Artigo recebido em: 28/09/2020 e aceito para publicação em: 14/12/2020

DOI: http://dx.doi.org/10.14488/1676-1901.v2111.4140 